\title{
ARTROSCOPIA DA ARTICULAÇÃO ESCAPULOTORÁCICA: RELATO DE CASOS
}

\author{
ARTHROSCOPY OF THE SCAPULOTHORACIC JOINT: CASE REPORTS
}

Carlos Vicente Andreoli ', Benno Ejnisman², Alberto de Castro Pochini ${ }^{3}$, Gustavo Cará Monteiro 4

Moisés Cohen ${ }^{5}$, Flávio Faloppa ${ }^{6}$

\section{RESUMO}

A artroscopia escapulotorácica é um procedimento que apresenta indicações restritas, para ressecção de corpos livres, tumores benignos, bursites e escápulas em ressalto. Os autores relatam quatro casos de artroscopia da articulação escapulotorácica; no primeiro caso, foi realizada apenas a visualização do tumor benigno (osteocondroma); no segundo caso, a ressecção artroscópica de um osteocondroma; no terceiro caso, a bursectomia artroscópica devido à bursite escapulotorácica; e no quarto caso, bursectomia e escapulectomia súpero-medial parcial artroscópica devido à escápula em ressalto.

Descritores - Escapula; Artroscopia; Humanos

\section{ABSTRACT}

Scapulothoracic arthroscopy is a procedure presenting restricted indications, for resecting free bodies, benign tumors, bursitis, and snaping scapula. The authors report four cases of scapulothoracic joint arthroscopy; in the first case, only a benign tumor (osteochondroma) could be visualized; in the second case, arthroscopic resection of an osteochondroma was found; in the third case, arthroscopic bursectomy due to scapulothoracic bursitis, and; in the fourth case, bursectomy and partial superomedial arthroscopic scapulectomy due to snaping scapula.

Keywords - Scapula; Arthroscopy; Human

plos portais mediais. Chan et $a l^{(4)}$, Lehtinen et $a l^{(5)} \mathrm{e}$ Van Riet et $a l^{(6)}$ descreveram técnicas e portais alternativos para artroscopia escapulotorácica.

A artroscopia escapulotorácica é um procedimento com indicações restritas. Os artigos da literatura referem-se a relatos de casos e séries com número reduzido de pacientes, sendo preconizada nos casos de síndrome da escápula em ressalto, descompressão de bursites escapulotorácicas causadas por impacto contra o ângulo súpero-medial da escápula, ressecção de corpo estranho, ressecção de tumores benignos e tratamento de dores crônicas refratárias ao tratamento conservador $^{(1-16)}$.

1 - Doutorando, Médico do Centro de Traumatologia do Esporte (CETE) do Departamento de Ortopedia e Traumatologia da Universidade Federal de São Paulo - Unifesp, São Paulo (SP), Brasil.

2 - Doutor, Médico do Centro de Traumatologia do Esporte (CETE) do Departamento de Ortopedia e Traumatologia da Universidade Federal de São Paulo - Unifesp, São Paulo (SP), Brasil.

3 - Doutorando, Médico do Centro de Traumatologia do Esporte (CETE) do Departamento de Ortopedia e Traumatologia da Universidade Federal de São Paulo - Unifesp, São Paulo (SP), Brasil.

4 - Médico do Centro de Traumatologia do Esporte (CETE) do Departamento de Ortopedia e Traumatologia da Universidade Federal de São Paulo - Unifesp, São Paulo (SP), Brasil.

5 - Livre-Docente, Professor Adjunto e Chefe do Centro de Traumatologia do Esporte do Departamento de Ortopedia e Traumatologia da Universidade Federal de São Paulo - Unifesp, São Paulo (SP), Brasil.

6 - Professor Titular do Departamento de Ortopedia e Traumatologia da Universidade Federal de São Paulo - Unifesp, São Paulo (SP), Brasil.

Trabalho realizado no Centro de Traumatologia do Esporte (CETE) do Departamento de Ortopedia e Traumatologia (DOT) da Universidade Federal de São Paulo (Unifesp). Correspondência: Dr. Carlos Vicente Andreoli, Rua Embaú, 87 - 04300-000 - São Paulo, SP. Tel.: 5579-3233. E-mail: andreolicruz@uol.com.br 
A anatomia artroscópica foi descrita nos trabalhos de Ruland et $a l^{(7)}$, por meio de estudos em cadáveres, relacionando as importantes estruturas neurovasculares, propondo portais seguros, evitando a lesão de estruturas nobres. A articulação escapulotorácica possui dois espaços triangulares, o espaço do serrátil anterior e o espaço subescapular, que são divididos obliquamente pelo músculo serrátil anterior. Os limites do espaço do serrátil anterior incluem o músculo serrátil anterior posteriormente, o músculo romboide medialmente e a parede torácica anteriormente. No espaço do subescapular encontra-se o músculo serrátil anterior anteriormente, o músculo subescapular posteriormente e a axila lateralmente.

No procedimento artroscópico o paciente é colocado em posição pronada, o braço em total rotação interna e o ombro em extensão (chicken wing position), na qual ocorre o aumento do espaço escapulotorácico ${ }^{(1,7)}$. O portal inicial de entrada situa-se medial ao ângulo da escápula ao nível da espinha escapulotorácica; um segundo portal é posicionado cerca de $4 \mathrm{~cm}$ abaixo do primeiro portal $^{(2)}$. O acesso ao ângulo superior da escápula, com os portais descritos, pode ser de difícil realização; em alguns casos, portais alternativos e seguros localizam-se superiormente à escápula ${ }^{(4,6)}$.

O objetivo do estudo é apresentar quatro casos clínicos do tratamento cirúrgico de afecções da escápula com a utilização da artroscopia da articulação escapulotorácica.

\section{RELATO DOS CASOS}

\section{Caso clínico 1 - Inspeção artroscópica}

Paciente do sexo feminino, 22 anos de idade, sexo feminino, universitária, praticante de ginástica de academia, apresentava queixa de dor e aumento de volume na região dorsal direita medial à borda medial da escápula havia um ano. A dor aumentava com exercícios e a região dorsal apresentava saliência volumosa na escápula aos movimentos.

Ao exame físico, não apresentava alteração de amplitude de movimento, porém, notava-se deformidade na região dorsal direita com presença de uma "escápula alada".

A radiografia da região escapular demonstrou a presença de massa sólida na borda medial da escápula. O estudo radiográfico foi complementado por meio da tomografia computadorizada (TC). Essa imagem foi considerada compatível com osteocondroma (Figura 1).

A indicação cirúrgica para paciente foi devida à presença da dor, da escápula alada e o tamanho do tumor benigno. A artroscopia escapulotorácica teve como objetivo visualizar o tumor benigno (osteocondroma), pois,

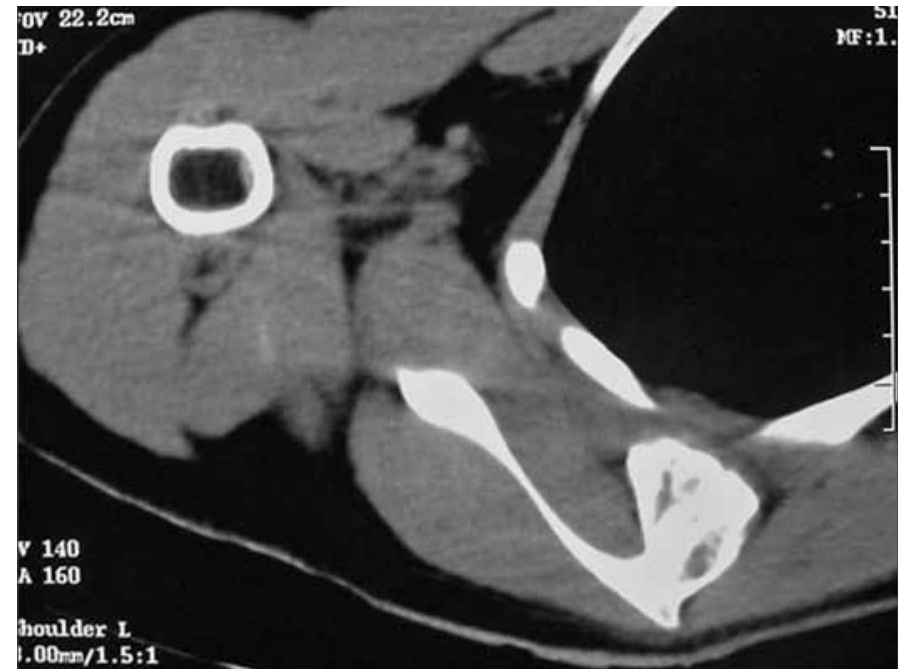

Figura 1 - Tomografia computadorizada da escápula evidenciando presença de osteocondroma na região medial

devido ao tamanho do tumor, sua ressecção por via artroscópica seria muito difícil.

A paciente foi submetida a uma artroscopia da articulação escapulotorácica para retirada da tumoração. Sob anestesia geral, foi posicionada em decúbito ventral com o membro afetado em rotação medial. O procedimento artroscópico permitiu a visão direta do osteocondroma, porém, devido ao tamanho do tumor, optou-se pela ressecção aberta com sua excisão completa (Figuras 2 e 3 ). O procedimento demorou 25 minutos.

As radiografias pós-operatórias evidenciaram a retirada total do tumor. Clinicamente, a paciente evoluiu sem dor e com melhora da deformidade, permanecendo assintomática com três anos de seguimento. A evolução do caso foi satisfatória. Esse foi o primeiro caso realizado pelo grupo, no qual foi obtida a visualização do tumor, porém, a sua ressecção foi por via aberta.

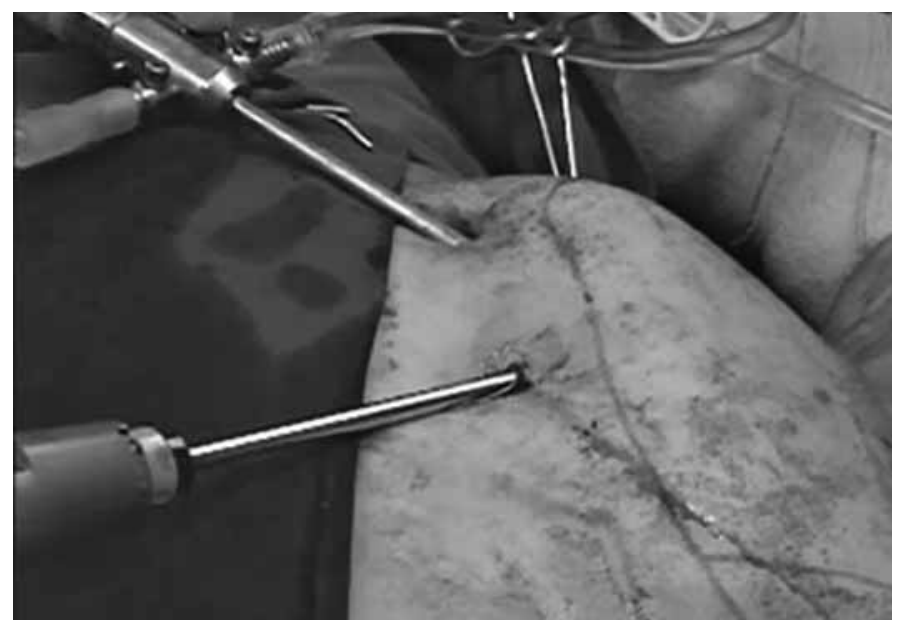

Figura 2 - Portais artroscópicos mediais para inspeção artroscópica da articulação escapulotorácica 


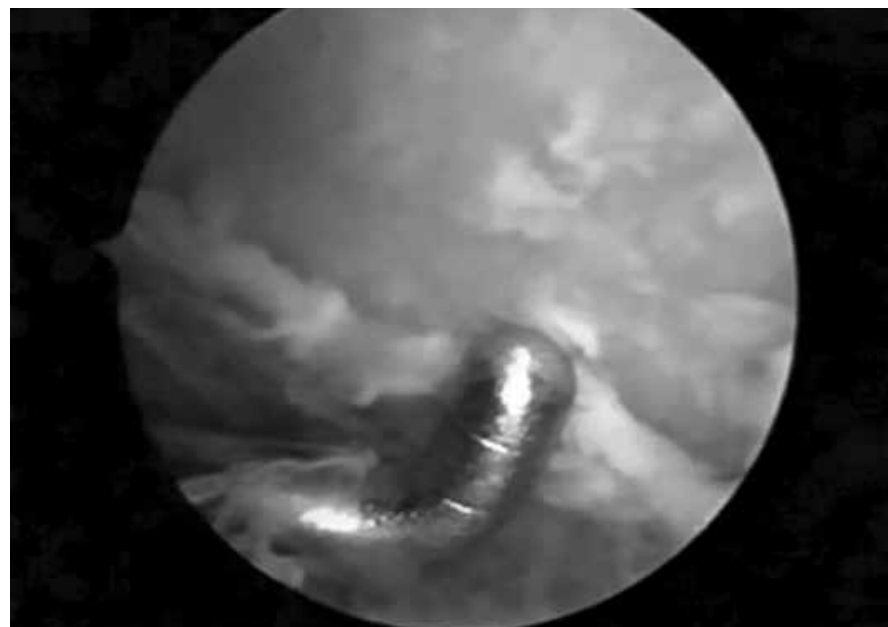

Figura 3 - Visualização artroscópica do osteocondroma

\section{Caso clínico 2 - Ressecção artroscópica de osteocondroma da escápula}

Paciente do sexo feminino, 17 anos de idade, sexo feminino, estudante, apresentava queixa de dor e crepitação na região da escápula esquerda havia oito meses. A crepitação foi progressiva junto com o aparecimento de dor aos movimentos.

Ao exame físico da escápula esquerda não apresentava alteração de amplitude de movimento, crepitação à palpação e discinesia escapular com presença de uma "escápula alada".

A radiografia de perfil escapular demonstrou a pequena massa sólida na região anterior do terço médio da escápula. A tomografia computadorizada (TC) complementou o diagnóstico, evidenciando massa sólida na região anterior do terço médio da escápula. Essa imagem foi considerada como compatível com osteocondroma (Figura 4). A indicação cirúrgica para a paciente foi devida à presença da dor, da escápula alada, à localização e tamanho do tumor benigno (osteocondroma). $\mathrm{O}$

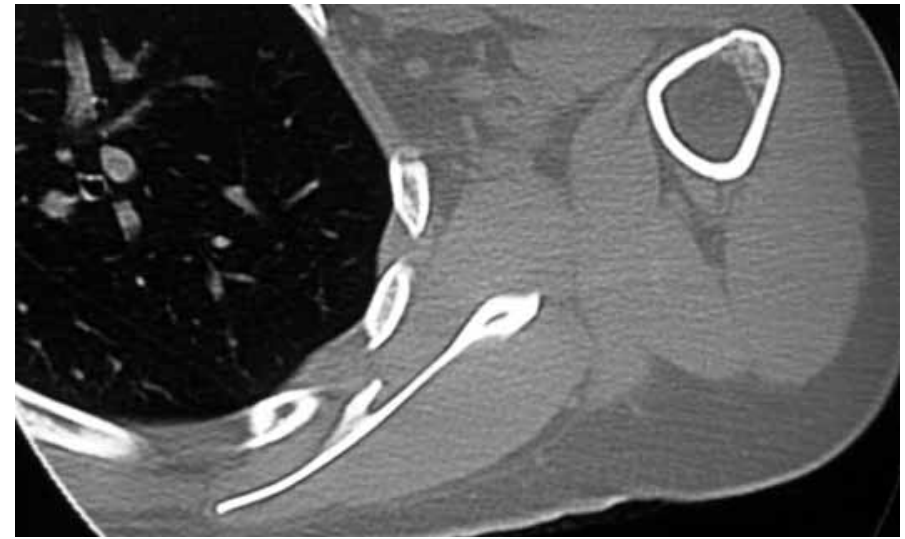

Figura 4 - Tomografia computadorizada da escápula evidenciando presença de osteocondroma na região central do terço médio

objetivo da artroscopia escapulotorácica foi ressecar o tumor benigno (osteocondroma) por via artroscópica.

A paciente foi submetida à anestesia geral, posicionada em decúbito ventral com o membro afetado em rotação medial, com coxim apoiado sobre o ombro afetado (Figura 5). O procedimento artroscópico permitiu a visão direta e ressecção completa do osteocondroma (Figuras 6a, b, c). O procedimento demorou 40 minutos;

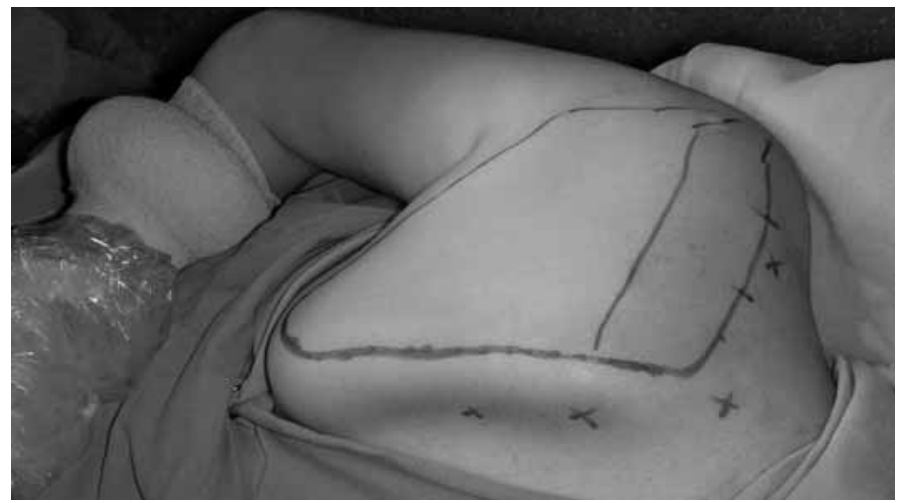

Figura 5 - Posicionamento do paciente em decúbito ventral com o braço em rotação medial e demarcação dos portais para artroscopia da articulação escapulotorácica
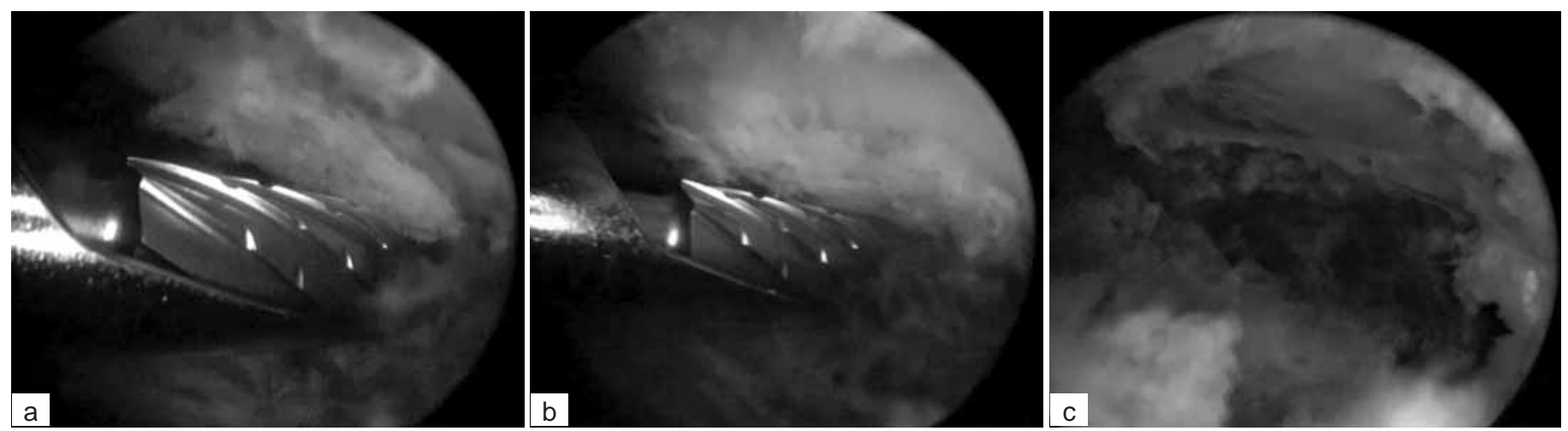

Figura 6 - a) Localização do osteocondroma e posicionamento para ressecção artroscópica; b) início da ressecção com lâmina de shaver para parte óssea; c) visão artroscópica da ressecção completa do osteocondroma 
a paciente apresentou edema acentuado da região da escápula (Figura 7).

As radiografias pós-operatórias evidenciaram a retirada total do tumor (Figura 8). Clinicamente, a paciente evoluiu sem dor e com melhora da crepitação e da deformidade, retornando à educação física após quatro meses. A evolução do caso foi satisfatória.

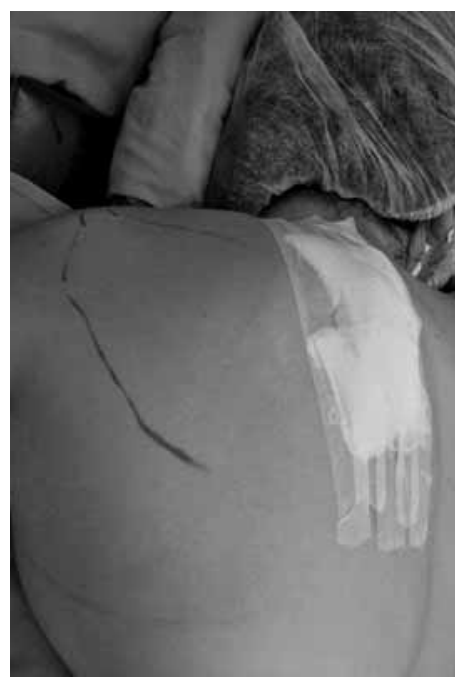

Figura 7 - Presença de edema acentuado na escápula pós-artroscopia da articulação escapulotorácica

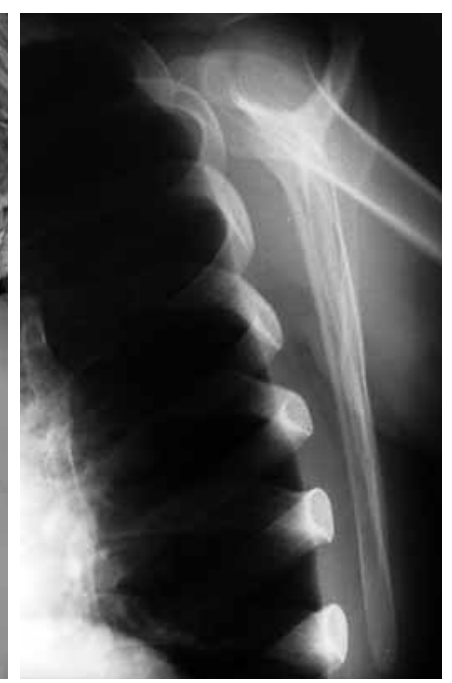

Figura 8 - Radiografia de perfil da escápula evidenciando a ressecção total do osteocondroma

\section{Caso clínico 3 - Bursectomia da escápula}

Paciente do sexo masculino, 36 anos de idade, trabalhador braçal, praticante de futebol amador, apresentava queixa de dor na região súpero-medial da escápula esquerda havia três anos, com piora com exercícios de musculação. Houve piora progressiva da dor, tornando-se contínua e incapacitante para o trabalho, mesmo com uso de analgésicos e anti-inflamatórios e realização de fisioterapia (65 sessões) e três infiltrações.

Após dois anos sem sucesso com tratamento clínico, foi afastado do trabalho, sendo realizadas duas infiltrações locais em três meses, sem melhora da dor. Ao exame físico apresentava dor à palpação na região súpero-medial da escápula esquerda, sem alteração de amplitude de movimento ou presença de deformidades.

As radiografias da região escapular não apresentaram alterações das estruturas ósseas. A ressonância magnética da escápula evidenciou processo inflamatório e tecido fibrótico na borda súpero-medial da escápula esquerda, imagem considerada compatível com bursite da escápula. A indicação da artroscopia da articulação escapulotorácica foi devida à persistência do quadro doloroso.
O paciente foi submetido à anestesia geral, posicionado em decúbito ventral com o membro afetado em rotação medial. Obteve-se ressecção total da bursa no ângulo súpero-medial da escápula. Uma agulha foi utilizada para localizar o ângulo, por meio de dois portais mediais; não foi realizada ressecção óssea local (Figuras 9,10 e 11). O procedimento demorou 26 minutos.

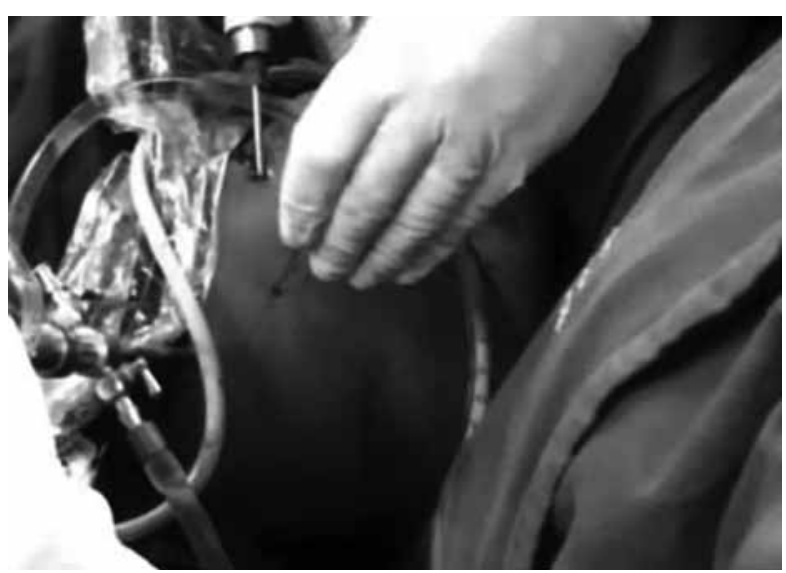

Figura 9 - Utilização de agulha para demarcar o ângulo súpero-medial da escápula durante artroscopia da articulação escapulotorácica

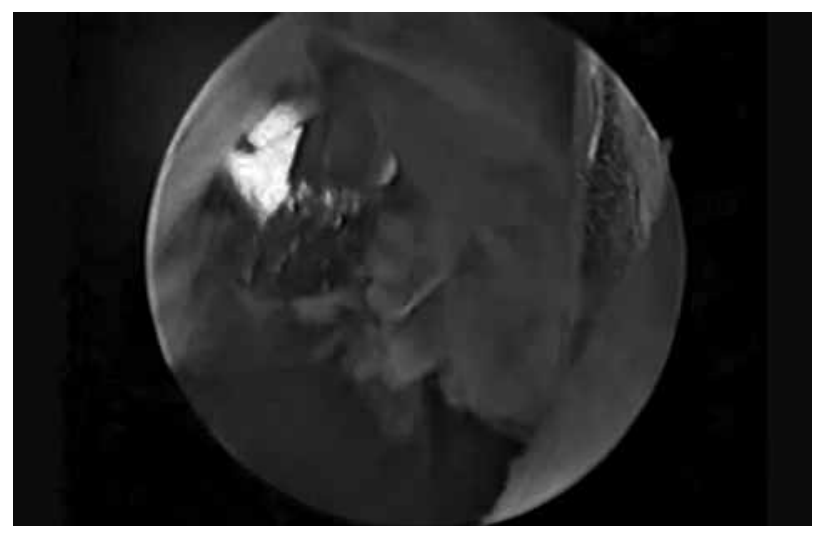

Figura 10 - Imagem artroscópica da bursectomia

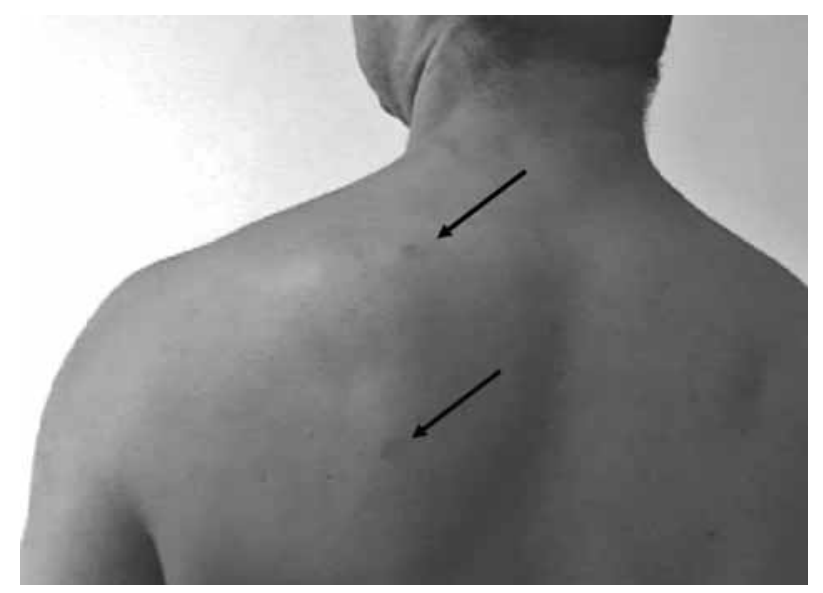

Figura 11 - Portais utilizados para bursectomia 
No pós-operatório, a radiografia e a ressonância confirmaram a retirada total da bursite da escápula. Clinicamente, o paciente apresentou-se assintomático após seis semanas. A evolução do caso foi satisfatória, o paciente retornando ao trabalho após três meses.

\section{Caso clínico 4 - Bursectomia e escapulectomia parcial}

Paciente do sexo masculino, 42 anos de idade, empresário, praticante de tênis e corrida, apresentava queixa de dor e volume na região dorsal esquerda havia quatro anos. A dor aumentava com a prática do tênis no saque e no forehand.

Ao exame físico, não apresentava alteração de amplitude de movimento, porém, notava-se dor à palpação da região súpero-medial da escápula esquerda (Figura 12). As radiografias da região escapular esquerda mostraram presença de saliência óssea na borda súpero-medial da escápula esquerda. $\mathrm{O}$ estudo radiográfico foi complementado por tomografia computadorizada (TC), evidenciando calcificação na borda súpero-medial da escápula esquerda (Figura 13). A ressonância magnética demonstrou a pre-

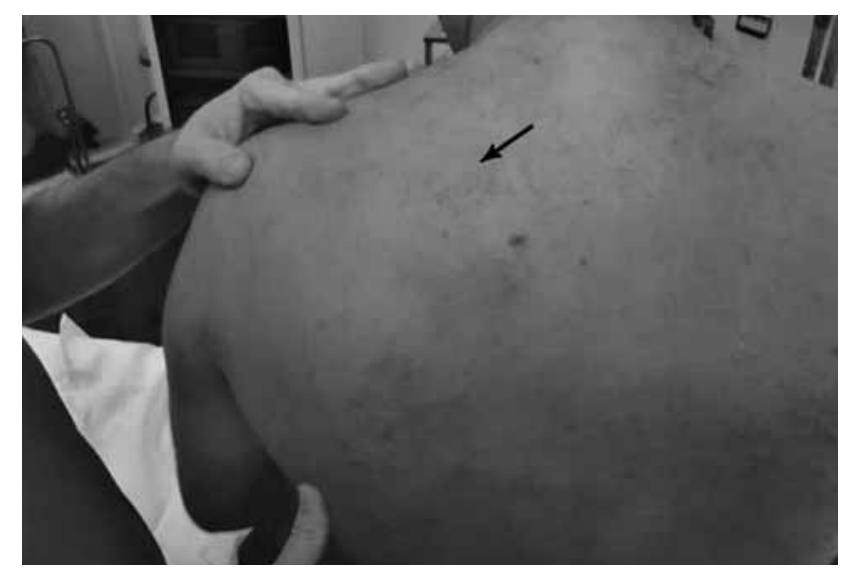

Figura 12 - Inspeção do local da dor e crepitação na articulação escapulotorácica (seta indicando) sença também de processo inflamatório local (bursite). A indicação da artroscopia da articulação escapulotorácica foi devida à persistência do quadro doloroso e à presença de saliência óssea na borda súpero-medial da escápula esquerda, compatível com escápula em ressalto.

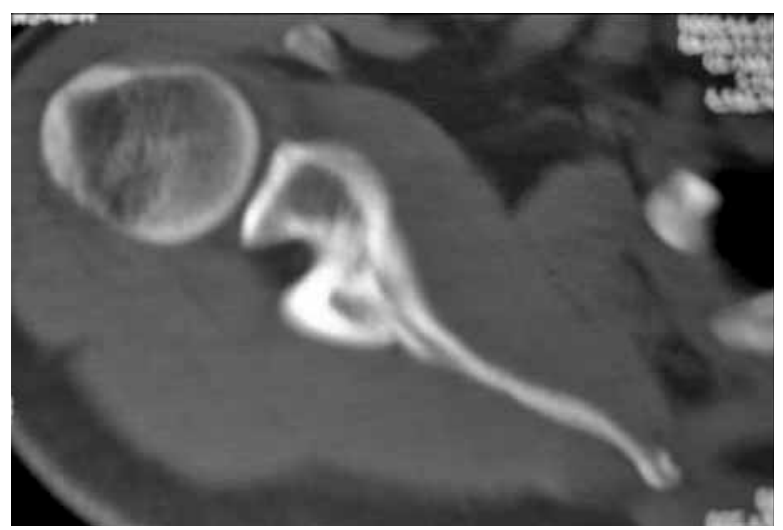

Figura 13 - Tomografia computadorizada da escápula evidenciando presença de calcificação no ângulo súpero-medial

O paciente foi submetido à anestesia geral, posicionada em decúbito ventral com o membro afetado em rotação medial para artroscopia da articulação escapulotorácica. Foram realizadas bursectomia e escapulectomia súpero-medial, com dois portais, um medial à espinha da escápula e outro com o portal de Bell (Figuras 14a, b, c). O procedimento demorou 39 minutos.

No pós-operatório o paciente evoluiu clinicamente com melhora da dor e reabilitação por dois meses, quando foi encaminhado à musculação e retornou ao tênis após três meses da cirurgia.

\section{DISCUSSÃO}

Os estudos relacionados com artroscopia da articulação escapulotorácica estão cada vez mais presentes na literatura ortopédica. As indicações clínicas são restritas, tornando esse procedimento incomum em nosso meio. Porém,
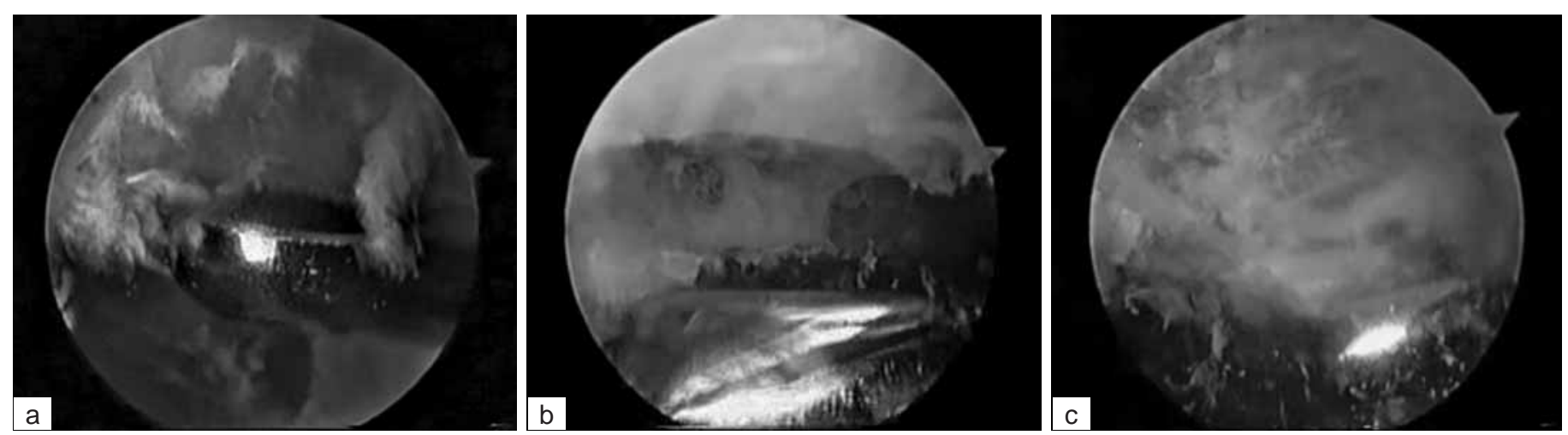

Figura 14 - a) Imagem artroscópica da bursectomia; b) ressecção com lâmina de shaver do ângulo súpero-medial da escápula; c) ressecção completa do ângulo súpero-medial da escápula 
com a melhora e definição da técnica artroscópica, casos específicos, tais como síndrome da escápula em ressalto, descompressão de bursites escapulotorácicas causadas por impacto contra o ângulo súpero-medial da escápula, ressecção de corpo estranho, ressecção de tumores benignos e tratamento de dores crônicas refratárias ao tratamento conservador, poderão ser tratados por esse método ${ }^{(1-16)}$.

O diagnóstico das afecções escapulotorácicas ainda é um desafio, nos casos de tumores benignos (osteocondroma), a presença do sintoma de dor e crepitação e de uma massa na radiografia ou tomografia computadorizada conduz ao diagnóstico. A ressecção total artroscópica foi realizada em um caso, seguindo os estudos anteriores de Kumar et $a^{(15)}$ e Fukunaga et $a^{(16)}$, devido à localização e tamanho do tumor; no primeiro caso, devido ao tamanho maior que $4 \mathrm{~cm}$, não foi possível realizar a artroscopia, apenas a visualização.

A artroscopia nos casos de bursites e impacto do ângulo súpero-medial da escápula é indicada com a falha do tratamento conservador por meio de medicação anti-inflamatória, reabilitação para equilíbrio muscular e infiltrações. A literatura, conforme relatos de Chan et al ${ }^{(4)}$, Lethinen et $a l^{(5)}$, Nicholson et $a l^{(9)}$, Sisto e Jobe ${ }^{(12)}$, indica o procedimento cirúrgico com a persistência do quadro doloroso. Nos casos de escápula em ressalto, a escapulectomia parcial súpero-medial é realizada associada ou não à bursectomia, conforme relatos de Millet et $a l^{(1)}$, Harper et $a l^{(3)}$, Carlson et $a^{(8)}$, Pavlik et al ${ }^{(10)}$ e Richards e McKee ${ }^{(11)}$

No terceiro caso apresentado (bursite escapulotorácica), foi realizada apenas a bursectomia devido à ausência de alterações ósseas nos exames complementares, em razão da persistência dos sintomas por mais de dois anos. No quarto caso (escápula em ressalto), foi realizada a bursectomia associada à ressecção parcial da escápula devido à persistência do quadro doloroso e à presença de saliência óssea na borda súpero-medial da escápula esquerda, compatível com escápula em ressalto.

Atualmente, estamos realizando um estudo da técnica para ressecção artroscópica da escápula em cadáveres,

\section{REFERÊNCIAS}

1. Millett PJ, Pacheco IH, Gobezie R, Warner JJP. Management of recalcitrant scapulotohracic bursitis: endoscopic scapulothoracic bursectomy and scapuloplasty. Techn Shoulder Elbow Surg. 2006;7(4):200-5.

2. Ciullo JV. Subscapular bursitis. Treatment of "snapping scapula" or "washboard syndrome". Arthroscopy. 1992;8:412-3.

3. Harper GD, Mcllroy S, Bayley JI, Calvert PT. Arthroscopic partial resection of the scapula for snapping scapula: a new technique. J Shoulder Elbow Surg. 1999;8(1):53-7.

4. Chan BK, Chakrabarti AJ, Bell SN. An alternative portal for scapulothoracic arthroscopy. J Shoulder Elbow Surg. 2002;11(3):235-8.

5. Lehtinen JT, Macy JC, Cassinelli E, Warner JJ. The painful scapulothoracic articulation: surgical management. Clin Orthop Relat Res. 2004;(423):99-105.

6. Van Riet RP, Bell SN, Fracs FA, Orth FA. Scapulothoracic arthroscopy. Techn Shoulder Elbow Surg. 2006;7(3):143-6.

7. Ruland LJ, Ruland CM, Matthews LS. Scapulothoracic anatomy for the arthroscopist. Arthroscopy. 1995;11(1):52-6.

8. Carlson HL, Haig AJ, Stewart DC. Snapping scapula syndrome: three case reports and an analysis of the literature. Arch Phys Med Rehabil. 1997;78(5):506-11. procurando desenvolvê-la e aplicá-la em casos clínicos, semelhante ao que ocorreu em outras articulações, tais como quadril, cotovelo, punho e tornozelo.

No ato artroscópico, a posição em decúbito ventral com o membro afetado em rotação medial (chicken wing position) é consenso da literatura ${ }^{(1-10)}$, sendo realizada em todos os nossos casos. Optamos também por colocar em coxim embaixo do ombro operado, aumentando ainda mais o espaço escapulotorácico, conduta não realizada nos artigos estudados.

Ruland et $a l^{(7)}$ descreveram os portais artroscópicos, em seus achados; os portais recomendados para a artroscopia cirúrgica devem ser inferiormente à espinha da escapula e três a quatro polpas digitais da borda vertebral da escápula, com a finalidade de proteção das estruturas neurovasculares no ângulo súpero-medial da escápula, proteção do nervo e artéria dorsoescapular, nervo espinhal acessório e para prover orientação perpendicular do artroscópio à parede torácica. Os portais realizados dependem da afecção escapulotorácica a ser tratada; no caso de uma bursite escapulotorácica, os portais de Bell, superior à escápula e medial à espinha da escápula, são utilizados para triangulação ${ }^{(6)}$. No tratamento de tumores benignos (osteocondromas), a diversidade de localização e tamanho na região da escápula tornam necessária a sequência de utilização dos portais variáveis.

A infusão de soro foi utilizada em dois casos por meio do equipo de quatro vias e, em dois casos, com a bomba de infusão, não foi observada diferença quanto ao grau de inchaço da articulação; porém, atualmente, optamos pelo equipo de quatro vias; o tempo cirúrgico não deve ser prolongado por mais de 45 minutos. Nas cirurgias, o inchaço excessivo deve ser uma preocupação constante, não sendo observadas complicações.

A artroscopia escapulotorácica é um procedimento em desenvolvimento; as indicações são restritas, porém, o domínio da técnica permitirá ampliar o uso e os procedimentos, tais como ressecções ósseas e releases musculares amplos.

9. Nicholson GP, Duckworth MA. Scapulothoracic bursectomy for snapping scapula syndrome. J Shoulder Elbow Surg. 2002;11(1):80-5.

10. Pavlik A, Ang K, Coghlan J, Bell S. Arthroscopic treatment of painful snapping of the scapula by using a new superior portal. Arthroscopy 2003;19(6):608-12.

11. Richards RR, McKee MD. Treatment of painful scapulothoracic crepitus by resection of the superomedial angle of the scapula. A report of three cases. Clin Orthop Relat Res. 1989;(247):111-6.

12. Sisto DJ, Jobe FW. The operative treatment of scapulothoracic bursitis in professional pitchers. Am J Sports Med. 1986;14(3):192-4.

13. Percy EC, Birbrager D, Pitt MJ. Snapping scapula: a review of the literature and presentation of 14 patients. Can J Surg. 1988;31(4):248-50.

14. Saboeiro GR, Sofka CM. Imaging-guided treatment of scapulothoracic bursitis. HSS J. $2007 ; 3(2): 213-5$

15. Kumar N, Ramakrishnan V, Johnson GV, Southern S. Endoscopically-assisted excision of scapular osteochondroma. Acta Orthop Scand. 1999;70(4):394-6.

16. Fukunaga S, Futani H,Yoshiya F. Endoscopically assisted resection of a scapular osteochondroma causing snapping scapula syndrome. World J Surg Oncol. 2007;5:37. 